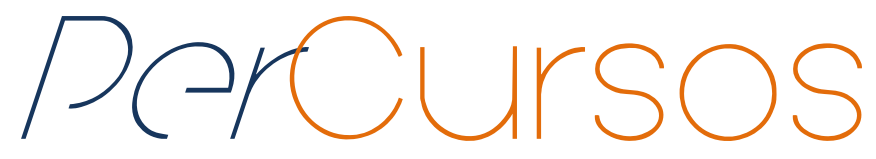

\title{
Quilombos na cena política: os experimentos organizativos do Maranhão-Brasil
}

\begin{abstract}
Resumo
Em meio às lutas de redemocratização nacional, na década de 1980, ganharam força reivindicações de povos indígenas, de camponeses e do movimento negro contemporâneo. Antes mesmo deste período de ápice participativo, registra-se intensa mobilização por parte de comunidades quilombolas, resistindo à grilagem e expropriação de seus territórios, organizando-se nas CEB's (Comunidades Eclesiais de Base) e recebendo influências da Teologia da Libertação, participando ativamente do sindicalismo rural e atuando junto ao movimento negro urbano. Assim, temse a formalização de direitos, aos então denominados, "remanescentes de quilombo", abrindo espaços de discussão sobre disputas territoriais no país, tendo como campo de visibilização destas comunidades, estudos realizados no MA em períodos anteriores e que subsidiam as discussões Constitucionais. No Maranhão, já na década de 1970, o CCN (Centro de Cultura Negra - MA) iniciou mapeamentos de práticas socioculturais e pertenças territoriais dessas comunidades, chamando atenção para sua extensão territorial e numérica no estado. Por sua vez, a mobilização crescente, a construção de um segmento organizado e a formação da ACONERUQ (Associação das Comunidades Negras Rurais Quilombolas), em 1997, como um "fórum de representação das comunidades quilombolas" frente às instâncias estatais, deram um caráter específico à luta por direitos na Nova República, com intensa participação em fóruns e instâncias deliberativas de políticas públicas. Em meados de 2011, demonstrando a existência de caminhos multifacetados de mobilização e estratégias entre as comunidades quilombolas, o MOQUIBOM (Movimento Quilombola do Maranhão) emergiu como um experimento de mobilização que evidencia o descrédito nas instâncias de participação, agindo, sobretudo, a partir de ocupações de prédios públicos e de denúncias quanto à morosidade de instituições.
\end{abstract}

Palavras-chave: Direitos Territoriais. Comunidades Quilombolas. Maranhão.
Igor Thiago Silva de Sousa

Doutorando em Sociologia na Universidade Federal do Rio

Grande do Sul - UFRGS.

Brasil

igorthiago.sousa@gmail.com

\section{Cindia Brustolin}

Doutora em Sociologia pela Universidade Federal do Rio

Grande do Sul - UFRGS.

Professora da Universidade

Federal do Maranhão - UFMA. Brasil

cindiabrustolin@gmail.com

\author{
Para citar este artigo: \\ SOUSA, Igor Thiago Silva de; BRUSTOLIN, Cindia. Quilombos na cena política: os experimentos \\ organizativos do Maranhão-Brasil. Revista PerCursos, Florianópolis, v. 19, n.39, p. 28 - 49, jan./abr. 2018.
}

DOI: $10.5965 / 1984724619392018028$

http://dx.doi.org/10.5965/1984724619392018028 


\title{
Quilombos in the political scene: the organizational experiments of Maranhão/Brazil
}

\begin{abstract}
During national redemocratization struggles in the 1980s, claims of indigenous peoples, peasants, and the contemporary black movement gained momentum. Even before this period of participatory summit, there was intense mobilization by quilombola communities, resisting land grabbing and expropriation of their territories, organizing themselves in the CEB's (Comunidades Eclesiais de Base) and receiving influences from Liberation Theology, actively participating in the rural syndicalism and working alongside the urban black movement. Thus, there is the formalization of rights, to the so-called "remnants of quilombo", opening spaces for discussion on territorial disputes in the country, having as a field of visibility of these communities studies carried out in Maranhão state in previous periods and that give material to constitutional discussions. In Maranhão as early as the 1970s, the CCN (Centro de Cultura Negra - MA) initiated mapping of socio-cultural practices and territorial affiliations of these communities, drawing attention to its territorial and numerical extension in the state. On the other hand, the growing mobilization, the construction of an organized segment and the formation of ACONERUQ (Associação das Comunidades Negras Rurais Quilombolas), in 1997, as a "forum of representation of the quilombola communities" as regards the state bodies, gave a specific character to the struggle for rights in the New Republic, with intense participation in forums and deliberative instances of public policies. In mid-2011, showing the existence of multifaceted ways of mobilization and strategies among quilombola communities, the MOQUIBOM (Movimento Quilombola do Maranhão) emerged as an experiment in mobilization that evidences discredit in the instances of participation, acting, above all, from occupations of public buildings and denunciations regarding the slowness of institutions.
\end{abstract}

Keywords: Territorial Rights. Quilombola Communities. Maranhão. 


\section{Introdução: reorganização do movimento negro e as entidades estaduais}

A experiência de reorganização do movimento negro se deu em términos do período de ditadura civil-militar, em meio às lutas pela redemocratização do país. $\mathrm{Na}$ década de 1970, eclodiu uma multiplicidade de organizações no movimento negro que trouxeram à tona a discussão sobre a questão racial que havia sido abafada desde 1964 com o golpe civil-militar e a (semi)clandestinidade. Eram centros de cultura, organizações de pesquisa, centros de recreação, centros de lazer, de assistência social e outros.

Em 1972, como aponta Domingues (2007), um grupo de estudantes e artistas formou o Centro de Cultura e Arte Negra (CECAN); a imprensa negra retoma suas atividades com a publicação e circulação dos jornais Árvore das Palavras (1974), o Quadro (1974), em São Paulo; Bilugaem São Caetano / SP. Em Porto Alegre, nasceu o Grupo Palmares (1971), o primeiro a defender a substituição das comemorações do dia 13 de maio para o dia 20 de novembro.

Além dessas experiências, surge em 18 de junho de 1978, o Movimento Unificado Contra a Discriminação Racial (MUCDR). Esse movimento, de caráter mais radical, redefine espaços de luta no cenário político da época, (SANTOS, 2006). Algumas influências nortearam tanto em plano nacional, quanto internacional, o surgimento do MUCDR, posteriormente abreviado para Movimento Negro Unificado (MNU). Cabe sinalizar a importância das lutas por direitos civis nos EUA, o surgimento dos Panteras Negras, a descolonização de países africanos e a influência da música soul, bem como casos de violência e repressão contra jovens negros no país.

Como parte dessa agenda de mobilização, setores do movimento negro brasileiro, principalmente no Maranhão e na Bahia, iniciam trabalhos voltados aos eixos rurais, com pautas sobre direitos territoriais específicos às comunidades negras quilombolas. Ao se remeter a direitos específicos, o movimento aludia a "dívida" que a nação brasileira teria com os afro-brasileiros em consequência da escravidão e não exclusivamente para pleitear a propriedade fundiária (LEITE, 2000), abordando, assim, a necessidade de um projeto nacional para com os afrodescendentes, como aponta Ilka Boaventura Leite: 
Desde os anos 30, algumas vozes militantes defendem fortemente a ideia de reparação da abolição como "um processo inacabado" e da "dívida", em dois planos: a herdada dos antigos senhores e a marca que ficou em forma de estigma, seus efeitos simbólicos, geradores de novas situações de exclusão. A exclusão como fato e como símbolo. Os militantes procuram ver o conceito de quilombo como um elemento aglutinador, capaz de expressar, de nortear aquelas pautas consideradas cruciais à mudança, de dar sustentação à afirmação da identidade negra ainda fragmentada pelo modelo de desenvolvimento do Brasil após a abolição da escravatura. (LEITE, 2000, p. 339)

O MNU iniciou seu trabalho com outras organizações negras já existentes, mobilizando e organizando ações, discussões e projetos com segmentos sociais negros. As ações do MNU serviram de influência para ações em diferentes estados do país, assim, em poucos anos se vê a efervescência de um conjunto de entidades influenciadas pelas experiências em São Paulo, o que leva ao processo de expansão do MNU para Pernambuco, Belo Horizonte, Rio Grande do Sul, bem como a criação de entidades como CCN, no Maranhão; da Associação Cultural Zumbi (ACZ), em Maceió; dos blocos afro Olodum e Malê Debalê, em Salvador; bem como a criação do Grupo Negro da Pontifícia Universidade Católica (PUC).

No que tange aos projetos e ações gestadas, coube às organizações do norte e nordeste, que vinham realizando encontros, projetos de mapeamento e formações políticas desde o final dos anos 70, com destaque para o CCN-MA e o CEDENPA (Centro de Estudos e Defesa do Negro do Pará), o papel de fornecedoras de subsídios sobre a existência de comunidades negras rurais, termo majoritário em uso até então. Nesse sentido, o CCN por mais que mantivesse contatos com o $\mathrm{MNU}$, não era propriamente uma expressão nordestina do desdobramento do movimento, mantendo-se uma entidade autônoma, com trabalhos e agenda própria.

Os trabalhos do CCN junto às comunidades quilombolas foram iniciados na década de 70 com o primeiro projeto elaborado com finalidade de construir entendimentos sobre esse segmento social, por parte de militantes negros; dando-se destaque, neste momento, ao papel de Mundinha Araújo', como elaboradora do esboço inicial. Esse

\footnotetext{
${ }^{1}$ Nasceu em São Luís, em 8 de janeiro de 1943. Formada em comunicação social pela Federação das Escolas
} 
projeto forneceu os primeiros levantamentos de material bibliográfico e a iniciativa de trabalhos de campo no interior do Maranhão, os quais posteriormente deram subsídios para a elaboração e efetivação do Projeto Vida de Negro (PVN) em meados dos anos 80.

Como desdobramento da atuação do Projeto, ocorreu o I Encontro das Comunidades Negras Rurais do Maranhão, realizado em 1986, em São Luís no sítio Pirapora, localizado no Bairro Santo Antônio. Neste evento, foram discutidas propostas de projetos a serem encaminhadas aos deputados federais (1988) e constituintes (1989) visando assegurar direitos específicos às comunidades quilombolas, como é descrito pelo PVN: “A principal reivindicação dos participantes desse encontro foi a garantia das terras de preto aos seus moradores, pois naquele período várias comunidades negras do Maranhão estavam sendo expulsas dos seus territórios" (PROJETO VIDA DE NEGRO, 2005, p. 47).

Como desdobramento desse encontro e das discussões que se sucederam, foi encaminhada à deputada federal e constituinte, Benedita da Silva (PT), uma proposta de garantia das terras às comunidades quilombolas, que foi apresentada na Assembleia Nacional Constituinte. A proposta foi aprovada, após discussões e redações distintas, dando origem ao artigo 68 do ADCT (Ato das Disposições Constitucionais Transitórias), da Constituição Federal, em 5 de outubro de 1988. Este ganho se dá a partir da realização de parcerias interestaduais entre o $\mathrm{CCN}$ e outras entidades do movimento negro como o CEDENPA, Movimento Negro do Rio de Janeiro e Associação Cultural Afro-Brasileira, que possibilitou a troca de experiências e projetos em comum (PROJETO VIDA DE NEGRO, 2005) e a garantia do artigo constitucional.

A partir desse trabalho do CCN através do PVN, iniciaram-se os processos de organização e luta das chamadas comunidades negras rurais quilombolas do Maranhão pelo cumprimento do artigo 68 do $\mathrm{ADCT}$, com o posterior desdobramento culminando com a criação de uma entidade representativa específica, a ACONERUQ. A pauta do “território quilombola”, com a expressão concreta através de disputas com latifundiários

Superiores do Maranhão em 1975. Foi fundadora do Centro de Cultura Negra do Maranhão (CCN), em 1979, a primeira vice-presidente da entidade, de 1980 a 1984. Foi diretora do Arquivo Público do Estado do Maranhão entre 1991 e 2003 (ALBERTI; PERREIRA, 2007, p. 31). 
e grileiros ocorrendo em municípios como Mirinzal, Codó, Alcântara e Itapecuru-Mirim, serviu de mote para a criação de uma entidade específica das comunidades quilombolas.

\section{A aprovação de direitos constitucionais}

As possibilidades de constituição de um cenário de avanços na afirmação de espaços democráticos e a realização de agendas públicas em torno da reparação das desigualdades fincadas nas relações raciais inaugura uma entrada complexa do reconhecimento das formas de apropriação territorial dos grupos negros no Brasil para os marcos legais e para o rol de direitos a serem assegurados.

Mesmo com o reconhecimento formal de direitos territoriais aos quilombolas, pela Constituição Federal de 1988, não foram instituídos nos anos posteriores à Constituição instrumentos jurídicos para fazer valer os direitos "consagrados" na carta, como definidos órgãos públicos competentes, instituídos ritos processuais etc. Permaneceu, num primeiro momento, um cenário de ausência de ritos específicos relacionados ao reconhecimento de direitos territoriais aos grupos negros.

As demandas surgidas no plano estatal foram encaminhadas de formas diversas: a partir da instalação de inquéritos no MPF; pela abertura de procedimentos administrativos junto à FCP; pela intervenção de órgãos estatais e de superintendências regionais do INCRA; por meio de ações judiciais (como os casos de Frechal - MA e Rio das Rãs - BA).

As disputas em torno do rumo que tomaria o reconhecimento de direitos às comunidades quilombolas foram impulsionadas pelas demandas das comunidades negras (como as comunidades de Frechal, no Maranhão, e a de Casca, no Rio Grande do Sul, entre outras) que chegavam ao Estado pós-1988 e pela pressão dos movimentos sociais. Em 1991, o advogado Dimas Salustiano da Silva (1996, p. 26) ligado ao movimento negro maranhense, enviou carta em nome da associação dos moradores das comunidades Rumo-Frechal (município de Mirinzal - MA) para o procurador-geral da república, solicitando que tomasse "as medidas cabíveis para que, nos termos do art. 68 do ADCT, seja emitido o título de propriedade". Apesar de não ter sido expedido o título de 
reconhecimento de domínio, como solicitado, a reivindicação resultou na criação de uma reserva extrativista por meio do decreto 536, de 21 de maio de 1992 (TRECCANI, 2006).

Para Dimas Salustiano da Silva (1996), além da garantia da permanência dos quilombolas nas terras, o caso de Frechal fornecia "parâmetros para que outras áreas [pudessem] pleitear judicial ou extrajudicialmente a aplicabilidade do dispositivo ora tão festejado". Os direitos requeridos pelo grupo (que chegou a ocupar a sede do IBAMA /Maranhão) tornavam-se "concretos e imediatos com a ação judicial de desapropriação proposta junto à $1^{\text {a }}$ Vara da Seção Judiciária da Justiça Federal do Maranhão pelo IBAMA, em razão na imissão provisória na posse deferida nos autos do processo citado" (SILVA, 1996, p. 56).

As diversas instâncias do Estado envolvidas e os tipos de procedimentos utilizados no encaminhamento das demandas de regularização de terras mostram que, inicialmente, não houve uma padronização dos procedimentos de regularização fundiária dos territórios quilombolas. Para Almeida (1998, p.129-130), o caráter múltiplo da tramitação dos processos de regularização das áreas de quilombos era ditado "pelas circunstâncias específicas de cada situação de conflito e pelo capital de relações sociais do movimento quilombola, ora acumulado no INCRA, ora no CNPT (IBAMA), ora na Fundação Cultural Palmares, ora em órgãos fundiários estaduais”.

O quadro normativo pouco consolidado em torno dos procedimentos a serem seguidos, como os caminhos distintos trilhados nos estados para o encaminhamento de demandas, revela mais do que a dificuldade de disciplinar em um corpo homogêneo a diversidade de casos: apontava para os desacordos em torno da amplitude da questão quilombola e os usos de artifícios políticos e jurídicos na produção de normatividades. Isso pode ser problematizado na trajetória de normas, pareceres, decretos expedidos para disciplinar a matéria; nas noções e conceitos colocados em jogo e na análise mais detida de peças de processos administrativos. 


\section{O movimento quilombola: a criação da ACONERUQ}

O cenário de conquistas, representado principalmente pela aprovação da Constituição Federal de 1988, impôs novos desafios aos movimentos sociais no meio negro. A abertura de possibilidades de institucionalização dos pleitos por titulação dos territórios, mas a não constituição de um rito administrativo ou a definição precisa dos trâmites e dos órgãos públicos responsáveis, exigiu "fazer acontecer" as titulações. O momento encarado como de "avanço" instaurava uma série de questionamentos em distintos setores e incitava a uma ação política incisiva junto aos órgãos públicos e às comunidades: quantas seriam as comunidades? Quais seriam os critérios de definição desse novo sujeito de direitos?

O CCN iniciou atividades relacionadas à atuação junto a comunidades quilombolas. Tendo como foco a realização de mapeamentos de usos e posses da terra e práticas socioculturais. A partir de 1991, os trabalhos passaram a estar voltados de forma mais direta sobre mecanismos de efetivação do artigo 68, do ADCT, da Constituição Federal. Assim, iniciou processos de formação política junto a jovens militantes do movimento negro e a moradores das comunidades quilombolas.

Com acúmulos políticos, após o IV Encontro das Comunidades Negras Rurais, Quilombos e Terras de Preto do Maranhão, realizado em abril de 1995, em São Luís, ocorre a criação da Coordenação Estadual Provisória dos Quilombos Maranhenses que era constituída por representantes dos municípios de Alcântara, Mirinzal, Cururupu, Codó, Itapecuru-Mirim, Penalva, Turiaçu, Brejo, Caxias e Bacabal (PROJETO VIDA DE NEGRO, 2005), o qual tinha por finalidade encaminhar seminários e capacitações de militantes nos municípios. Por sua vez, entre lideranças quilombolas, havia consenso sobre a necessidade de criação de uma entidade com abrangência por todo Maranhão, bem como uma institucionalidade que superasse os limites de uma Coordenação Provisória.

Assim, a ACONERUQ surge em 1997, após seminários municipais ocorridos nos municípios de Cururupu, Mirinzal, Alcântara e Turiaçu, ao longo do ano de 1996, e após a realização do V Encontro das Comunidades Negras Rurais no Maranhão, somando-se 10 
anos de realização desse tipo de encontro e discussão. Após a oficialização da ACONERUQ, ocorre a primeira eleição para a coordenação estadual, sendo Ivo Fonseca eleito para a gestão de 1997 a 2003. Ivo Fonseca relata que:

O foco principal era trabalhar para que as comunidades conquistem seus territórios e no período que eu fui coordenador eu encaminhei muitos processos para o INCRA e de outro lado que nós trabalhávamos era a questão da formação política nas comunidades, era a base entender o processo na ACONERUQ, entender a formação. Entender o processo vindo de baixo para cima e não de cima para baixo, então nós tínhamos essa capilaridade. Outro ponto que nós trabalhávamos era a questão das normas constitucionais. Quando a ACONERUQ começa nós também passamos por isso em nível nacional, porque não adiantava nós estarmos aqui e as portas estarem fechadas quanto a esses ordenamentos. Nós também trabalhamos políticas básicas como educação, saúde, estradas.

Ao mesmo tempo em que eram encaminhados processos de titulação aos órgãos fundiários responsáveis, a ACONERUQ começou a estabelecer articulações com governos estadual e federal, a fim de negociar políticas públicas específicas, como educação, saúde, assistência social diferenciada, cestas básicas, moradia, infraestrutura, etc. Foram firmadas parcerias com o Banco Mundial (BM) e governos estaduais para a realização de encontros.

Com o término da primeira gestão da ACONERUQ, em 2003, iniciam-se problemas relativos à expansão das atividades da entidade e ao crescimento de demandas de comunidades quilombolas no Maranhão. A liderança de Ivo Fonseca destaca as tensões:

Acho que criação do movimento passou por uma gestão e a gestão se fechou. Não dava resposta para base [...]. Têm pessoas que não se afinavam com a demanda, com os objetivos da ACONERUQ e que começou a falar que não [se] fazia nada, que as pessoas estavam enganando o povo.

De um lado tem-se o ganho na organização das demandas e representatividade das comunidades quilombolas frente a instâncias públicas municipais, estaduais e federais, de outro, passam a surgir problemas em termos de representação da 
ACONERUQ com as comunidades quilombolas ligadas a esta entidade. Essas questões irão influenciar nas formas de mobilização política, permitindo a emergência de novas maneiras de organização e de estratégias a serem adotadas.

\section{O decreto de 2003 e novos fôlegos aos processos}

Na entrada do governo de Luís Inácio Lula da Silva, do PT, em 2003, foi criado um grupo de trabalho interministerial com a finalidade de discutir uma nova proposta normativa para a operacionalização do artigo 68 do ADCT. O grupo foi instituído para a proposição de uma nova normativa pelo Decreto de 13 de maio de 2003, e coordenado pela Casa Civil da Presidência da República e pela Secretaria Especial de Políticas para a Promoção da Igualdade Racial. Contou, ainda, com representantes de órgãos do governo e comunidades quilombolas.

Os trabalhos realizados pelo grupo interministerial resultaram na expedição de um novo decreto, em 2003, e na revogação do decreto de 2001. O Decreto Federal $n^{\circ} 4.887$, de 20 de novembro de 2003, transferiu para o INCRA a competência para instaurar os procedimentos necessários à regularização fundiária dos territórios quilombolas. No Decreto $4.887 / 2003$, foram retomados os princípios norteadores do projeto-de-lei vetado no governo Fernando Henrique Cardoso $^{2}$ e, em parte, as expectativas dos agentes engajados na promoção dos direitos às comunidades quilombolas, principalmente a “auto-definição”, como condição para a identificação dos remanescentes de quilombos; a noção de território, para designar a "área ocupada"; e a necessidade da desapropriação de áreas particulares incidentes no território identificado.

Além de consagrar a auto-definição, o decreto estabeleceu outros critérios para que um grupo social reivindique a condição de "remanescentes das comunidades dos quilombos": "trajetória histórica própria”, "relações territoriais específicas" e “ancestralidade negra relacionada com a resistência à opressão histórica sofrida”. O cenário favorável conformado pela afirmação jurídica da expansão das novas demandas

\footnotetext{
${ }^{2}$ O presidente Fernando Henrique Cardoso (PSDB) cumpriu dois mandatos consecutivos na presidência da república que compreendem o período de janeiro de 1995 a dezembro de 2002.
} 
dentro do Estado foi corroborado pela ratificação realizada pelo Brasil da Convenção 169 da OIT, em 2005.

A afirmação de critérios como a "auto-definição", a capilaridade do INCRA com sedes em todos os estados e a organização dos movimentos sociais que atuam na luta permitiram uma significativa expansão no número de procedimentos instaurados. Em 2007, no INCRA, já haviam sido instaurados 450 processos de regularização territorial.

Com as novas normas, houve uma relativa padronização dos procedimentos a serem seguidos no reconhecimento das áreas e na regularização fundiária. Os procedimentos, dentro do INCRA, foram regulamentados inicialmente pelas instruções normativas: a IN 16/2004 e a IN 20/2005, que mantiveram as noções constantes no Decreto $4.887 / 2003$.

Entretanto, apesar das expectativas geradas com as mudanças ocorridas na entrada do governo Lula, nos primeiros cinco anos foram tituladas apenas cinco comunidades. Se o instrumento foi julgado mais adequado pelos atores inseridos no processo, as titulações de terras não aconteceram no momento. Até 2008, foram assinados apenas dois decretos desapropriando terras particulares, referentes às Comunidades Família Silva, em Porto Alegre/RS, e Caçandoca, São Paulo. As expectativas e possibilidades visualizadas não se consagraram em números. O governo passou a ser acusado de permanecer "preso às amarras burocráticas e às pretensas discussões jurídicas que emperram o andamento dos processos” (Comissão Pró-índio, 2007).

\section{Instabilidade institucional da questão quilombola}

A expedição do decreto 4.887/2003 abriu espaço para a homogeneidade dos procedimentos de regularização fundiária dos territórios quilombolas. Apesar de uma série de indefinições ainda perpassarem os atos a serem realizados para a titulação das terras, a maior parte dos procedimentos que tramitavam em instâncias diversas (MPF, Fundação Cultural Palmares) ${ }^{3}$ passaram para o INCRA.

\footnotetext{
${ }^{3}$ Criada em 22 de agosto de 1988, pelo o Governo Federal, a Fundação Cultural Palmares (FCP) é uma
} 
Contudo, quando começou a se consolidar um rito administrativo que condensava as exigências, os pressupostos, as dificuldades para a construção de uma política governamental em torno dos territórios quilombolas, novos questionamentos passaram a ser colocados. Já em 2005, o $\mathrm{PFL}^{4}$ impetrou uma Ação Direta de Inconstitucionalidade (ADI) alegando a inconstitucionalidade tanto da expedição do decreto, quanto do conteúdo da referida norma. Nos anos seguintes, principalmente em 2007, iniciou-se uma campanha nos meios de comunicação de massa contra a política de reconhecimento e contra o decreto expedido no governo Lula. E, em 2008, o decreto passou a ser alvo de questionamentos no Legislativo e dentro das próprias instâncias governamentais, o que culminou numa proposta de alteração da Instrução Normativa do INCRA.

Justamente quando os procedimentos administrativos de regularização fundiária começam a ganhar expressão, os instrumentos normativos tornam-se alvos de acirradas discussões. Na tentativa de desmantelamento dos instrumentos vigentes - o Decreto 4.887/2003 e a Instrução normativa 20 do INCRA - foram impetradas ações judiciais, legislativas e administrativas que visam modificar tanto a definição de categorias presentes no texto legal como anular os procedimentos de regularização fundiária em curso.

No final de 2007, as pressões contra a revogação do Decreto 4.887/2003 foram, em parte, transferidas para a alteração da norma interna do INCRA que regulamentava o processo de reconhecimento e regularização fundiária das terras de quilombos: a IN 20. 0 governo federal institui um Grupo de Trabalho composto por diversos órgãos de Estado e coordenado pela AGU com o objetivo de identificar "os problemas existentes, causadores de controvérsias administrativas entre órgãos e entidades da Administração Federal, de empecilhos ao implemento de políticas públicas traçadas em prol de remanescentes de comunidades de quilombos" e apresentar sugestões.

entidade vinculada ao Ministério da Cultura (MinC). Tem entre as atribuições a valorização das manifestações culturais e artísticas negras brasileiras como patrimônios nacionais; entre tais está o reconhecimento e emissão de certificados a partir da auto-definição das comunidades quilombolas, o que Ihes assegura formalidade nos processos de titulação territorial e acesso a políticas públicas.

4 O Partido da Frente Liberal (PFL) foi um partido político brasileiro fundado em 1985, em meio às articulações que elegeram Tancredo Neves à presidência da República. Em 2007, foi refundado com o nome de Democratas (DEM). 
Na audiência pública, promovida pela sexta câmara do Ministério Público Federal, em 24 de setembro de 2007, no plenário da Câmara dos Deputados em Brasília, enquanto quilombolas de todo o país agitavam as bandeiras em defesa do Decreto 4.887/2003, um novo embate se anunciava. O governo não cederia às pressões em torno da revogação, porém havia decidido congregar esforços no "aperfeiçoamento" de atos normativos menores para “dirimir" conflitos e "assegurar' juridicamente a política governamental (BRUSTOLIN, 2015). Quem anunciava a boa nova era o Consultor da AGU, Ronaldo Sales, que coordenou o grupo de trabalho encarregado de buscar soluções e construir a nova instrução normativa.

Em outubro do mesmo ano, a AGU promoveu o Seminário Regularização Fundiária dos Territórios Quilombolas em Brasília, direcionado principalmente para técnicos do INCRA e procuradores federais lotados nas PFE-INCRA. O objetivo de familiarizar procuradores e técnicos para os procedimentos relativos ao reconhecimento da questão quilombola perdeu o norte para a pauta que, se não era, tornou-se a principal - a mudança da normativa.

Os pontos apresentados por Ronaldo Sales (representante da AGU), no seminário, convergiram principalmente para o aumento do controle sobre os procedimentos. A emissão da Certidão da Palmares passou a ter como função "checar" a auto-definição dos grupos. O segundo ponto levantado diz respeito ao maior controle por parte dos órgãos ambientais sobre os procedimentos e o terceiro, à necessidade de critérios objetivos na produção dos relatórios técnicos. As medidas de "segurança" da política seriam complementadas ainda com a exigência de "imparcialidade daqueles técnicos que elaboram esses relatórios". E, no caso de controvérsias entre órgãos públicos, a solução não caberia mais ao "Comitê de decisão regional [feito dentro INCRA nas superintendências regionais]", mas à "AGU". Isso permitiria "assegurar o devido processo legal e assegurar o contraditório".

A morosidade dos processos e as novas formas de controle legitimadas a partir da “segurança jurídica" dos procedimentos começaram a minar um cenário de expectativas em torno da titulação dos territórios quilombolas no Brasil. A mudança normativa, juntamente com todos os questionamentos e pressões da bancada ruralista (ações, 
depoimentos em jornais, projetos legislativos, PECs), apontava para um freio na consolidação da política fundiária para os territórios negros. Boa parte dos recursos para a política fundiária destinados às superintendências regionais do INCRA foram devolvidos ao final de cada ano orçamentário aos cofres da união pelas dificuldades de avançar nas etapas.

\section{"Na lei ou na marra nós vamos ganhar": O MOQUIBOM}

No Maranhão, a titulação dos territórios quilombolas, seguindo o cenário nacional, não avançou. ${ }^{5}$ Apesar do protagonismo do movimento negro no estado, das ações da ACONERUQ, das articulações das comunidades quilombolas, foram poucas as terras desapropriadas para a titulação dos territórios e mesmo no caso das desapropriações, nenhum território que tivesse áreas particulares para serem desapropriadas foi totalmente titulado.

Acumularam-se processos parados e queixas sobre a ineficiência do INCRA/MA. A morosidade no andamento dos processos de titulação de terras, somada à violência no campo, acirraram as dúvidas colocadas sobre as titulações dos territórios, sobretudo, no que tange ao interesse estatal em assegurar tais direitos ou mesmo a validade dos compromissos assegurados desde 1988.

Dentro desse cenário de descrença por parte de lideranças quilombolas no encaminhamento da política governamental para a regularização fundiária dos territórios quilombolas e de certa crise de representação da ACONERUQ, com críticas sendo realizadas tanto por lideranças do próprio movimento negro, através de figuras importantes do $\mathrm{CCN}$, quanto por outros setores, desvinculados propriamente desta agremiação, mas representativos junto a comunidades rurais, eclode um movimento

\footnotetext{
5 Segundo dados da Comissão Pró-índio de São Paulo (http://www.cpisp.org.br/terras/html/por_que_as_titulacoes_nao_acontecem.aspx, acessado em janeiro de 2018), poucos processos administrativos avançaram na produção das peças técnicas e nenhum território que exige a desapropriação das terras particulares foi totalmente titulado no estado do Maranhão.
} 
social, caracterizado pela luta pela efetivação das garantias constitucionais asseguradas através do artigo 68 do ADCT, o MOQUIBOM (Movimento Quilombola do Maranhão).

Já em 2011, este movimento passa a centrar suas críticas em situações de assassinatos de lideranças rurais no Maranhão e na morosidade na titulação territorial por parte dos órgãos competentes e na ausência de uma representação formal das comunidades quilombolas capaz de abarcar as diferentes regiões do estado (SOUSA, 2016, p. 64). O movimento foi ganhando visibilidade no meio político pelas estratégias de ação distintas, demonstrando a possibilidade de uma nova organização das comunidades quilombolas, como aponta Almirandir Madeira, morador da comunidade de Charco em São Vicente Férrer:

Nós não tínhamos representantes, pois como o atual governo diz, o representante dos negros é a ACONERUQ, então, não se tinha representação nenhuma, de um movimento social. Já tinha essa conversa de criação de um movimento com o pessoal da CPT nós (se) reunia em serrano e com isso a gente foi conversando com as comunidades, achamos que tinha a necessidade de nos representar, por isso fundamos - MOQUIBOM porque é ele a representação das comunidades quilombolas do Maranhão.

Ao atribuir a representatividade das comunidades quilombolas no Maranhão apenas à ACONERUQ, num estado com muitas comunidades quilombolas, o governo estadual conseguia uma justificativa para não escutar e atender a pluralidade de situações e demandas que emergiam desses grupos em distintas regiões. O MOQUIBOM se apresenta, então, como mais uma possibilidade da abertura de canais de comunicação e enfrentamento que permitiam ampliar o espaço da representação dos grupos e as estratégias até então empreendidas.

O MOQUIBOM angariava destaque a partir de estratégias envolvendo passeatas e, sobretudo, ocupações prolongadas de prédios de órgãos públicos responsáveis pela regularização fundiária quilombola, tanto em nível estadual, como em nível federal.

O surgimento do movimento está relacionado aos trabalhos da CPT junto a comunidades rurais e quilombolas no interior do Maranhão, mais especificamente, na 
região da Baixada Maranhense, onde o movimento nasce. Os trabalhos concentram-se na difusão das garantias Constitucionais existentes desde 1988, bem como, no auxílio às comunidades nos processos de auto-identificação e elaboração de relatos sintéticos a serem enviados à FCP, como forma de assegurar a obtenção do certificado emitido pela Fundação, um dos passos no processo de titulação territorial das comunidades quilombolas.

Assim, as ações do MOQUIBOM organizam-se em pequenos encontros que ocorrem nas comunidades quilombolas, pequenas ações em nível local na organização de demandas, bem como em encontros maiores, que ocorrem com a troca de experiências e vivências, a partir da construção de laços e da demonstração de pertenças étnicas comuns e situações de opressão compartilhadas por esses sujeitos. Como situa Marivânia Furtado:

Reunidos a partir da mística da terra como dom de Deus e direito de todos que dela precisam, o primeiro encontro da articulação MOQUIBOM aconteceu no sítio dos "padres" em Mangabeira, povoado de Santa Helena. Embalados e motivados por cânticos que denunciam o descaso do poder público e a necessidade de luta dos despossuídos, essa articulação marcou o primeiro semestre de 2011 com mobilizações jamais vistas, sobretudo por se tratar de um movimento quilombola. (FURTADO, 2012, p. 260-261)

As ações da CPT se dão principalmente pela interlocução que a entidade confessional tem para com as comunidades rurais, pelo prestígio gozado pelos padres e pelo histórico de atuação destes na mediação de conflitos e na resolução de questões. Assim, a CPT funciona como um foco de mediação entre as comunidades quilombolas e o Estado, na medida em que ocorrem conflitos fundiários.

As comunidades que iniciaram o processo de criação do MOQUIBOM alegavam estarem descobertas, sem atenção e trabalhos em seus municípios e localidades, sem saber como agir ou garantir seus direitos. Reclamavam, entre outras coisas, de desconhecimento e falta de formação para "defender seus modos de vida" e de conhecimentos sobre os trâmites formais no processo de titulação territorial. Conforme 
situa Zilmar Pinto Mendes, presidente da Associação Quilombola do Charco, município de Serrano:

O MOQUIBOM veio para que as comunidades acordassem, principalmente as lideranças, porque tinha muita liderança que não sabia o que fazer, queria pleitear a luta, mas não sabia como e onde ir buscar a solução. Então, o MOQUIBOM não veio trazer a solução, mas sim minimizar um pouco os problemas que tavam acontecendo nas comunidades.

Muitas lideranças comunitárias se sentiam desemparadas quanto a como lidar com conflitos e demandas oriundos de seus territórios, tendo dificuldades de estar à frente de processos de gestão de associações de moradores e pautas por direitos. Muitas destas lideranças alegavam desconhecimento sobre garantias constitucionais e marcos regulatórios relativos ao processo de titulação, a saber, o artigo 68 do ADCT e Decreto 4887. Conforme Gil Quilombola, liderança do MOQUIBOM:

O MOQUIBOM é um ombro amigo que surgiu para as comunidades quilombolas do Maranhão. Para [se] ter uma ideia, desde 1988 caía a lei, o artigo 68 da Constituição, até então ninguém debatia profundamente esse artigo, o próprio decreto 4.887 também não era debatido. É com o MOQUIBOM que essas coisas, esses debates vêm à tona. $E$ isso fica fácil da gente visualizar, as comunidades precisavam de um ombro amigo. Quando a gente faz o primeiro acampamento lá no INCRA é aí que começa a vir comunidade de toda parte do Maranhão, surge a notícia que tem um movimento quilombola do Maranhão, o MOQUIBOM, está acampado no INCRA em busca de titulação do território quilombola e as comunidades começam a aparecer; justamente buscando aquele ombro amigo, porque o MOQUIBOM ele é diferente.

A partir da fala de Gil Quilombola, a criação do MOQUIBOM representa a possibilidade de um amplo debate em termos das garantias constitucionais, bem como a luta para que tais garantias sejam postas em prática, através do tensionamento e da pressão social junto ao INCRA. Nesse sentido, o MOQUIBOM seria um "ombro amigo" na medida em que representa para as comunidades em situações de conflitos fundiários, 
uma possibilidade de extrapolar as realidades vivenciadas, uma forma de trazer à tona publicamente a realidade vivida e as privações passadas em meio a conflitos nos territórios frente a outras instâncias e órgãos. O MOQUIBOM se apresenta como um veículo de expressão das indignações e um novo modo de expressão do movimento quilombola.

Nesse sentido, a estratégia de ocupações do INCRA pode ser vista como uma forma de tornar públicas as situações de perseguições a lideranças quilombolas, de promover debates sobre as situações vivenciadas por estas comunidades, um meio de tentar pressionar instâncias estaduais e federais, e produzir um sentimento de pertencimento a um grupo político organizado.

\section{Enfrentamentos, ações e o alargamento das margens da política}

A ACONERUQ e o MOQUIBOM constituem dois esforços de representação das comunidades quilombolas no Maranhão e de abertura de espaços de enunciação. Ambos representam, em boa medida, cenários distintos e expectativas quanto à atuação do Estado. Com formas específicas de atuação e abrangência junto aos grupos, permitem pensar em momentos e estratégias distintos de luta. Num primeiro momento, que tem a ACONERUQ como principal protagonista, a "questão quilombola", aparece como uma grande possibilidade de avanço institucional na democratização da terra e no reconhecimento das comunidades negras, de suas especificidades étnicas, como na construção de políticas específicas. Parecem estar em jogo, os desafios de adentrar um Estado racista, historicamente excludente para os grupos negros, representando uma certa crença na possibilidade de um "novo Estado" que contemple a titulação dos territórios quilombolas. Em boa medida, isso se apresenta na possibilidade de participação em fóruns, espaços deliberativos, mesas, na execução/gestão de políticas públicas e convênios múltiplos, bem como, uma interlocução privilegiada com instâncias estatais.

Num segundo momento, quando a política de regularização fundiária sofre vários ataques, quando os processos de regularização fundiária não avançam, emerge à cena 
pública, o MOQUIBOM. De cunho mais contestativo e ligado à CPT, passa a atuar em confronto com instâncias estatais, rejeitando a institucionalidade de outrora e apontando como insignificantes a presença em espaços deliberativos, realizando ocupações de prédios públicos, passeatas, fechamento de estradas e vias ferroviárias, evidenciando processos de violência no campo e exigindo o estabelecimento de compromissos e agendas na regularização fundiária. Está em jogo a visibilização de uma política não efetivada, de um Estado que desrespeita direitos garantidos às comunidades negras. Isso se faz visível em protestos em frente à sede do Governo do Estado, do Tribunal de Justiça do Maranhão, em protestos e ocupações prolongadas de órgãos fundiários como INCRA e ITERMA (Instituto de Colonização e Terras do Maranhão) a partir de 2011. Evidenciando, de um lado, a descrença no cenário de "garantias de direitos", quanto apontando que “caminhos de mobilização se abriam”.

Os processos de titulação dos territórios quilombolas pouco avançaram nos dois momentos. De 2011 a 2016, mesmo com a forte pressão social do MOQUIBOM, com a ocupação dos prédios públicos, com o fechamento de estradas, não ocorreram mudanças significativas em termos de acesso à terra. Os ganhos revelaram-se maiores na denúncia e na visibilização da inércia do Estado frente à titulação dos territórios. Os acordos firmados durante a greve de fome de sete dias, em 2015, na sede estadual do INCRA/MA, ou mesmo, na ocupação do INCRA/MA, em 2013, que contou com uma intensa ocupação e denúncias de assassinatos no campo, com a presença do staff do governo federal, não alteraram o número irrisório de comunidades quilombolas com títulos definitivos no estado.

Cabe sinalizar que, se de um lado, foram obtidos avanços no que tange a institucionalização dos direitos quilombolas a partir de 1988, com relativas vitórias em termos de decretos e regulações estatais, os avanços se configuram à margem de efetivações reais, com uma institucionalização "periférica”, ou seja, com possibilidades tímidas de ocorrência, figurando entre as comunidades como uma "conquista pela metade", na medida em que estas se apresentam ora como uma "promessa", ora como um "dever" institucional abstrato que não se concretiza com facilidade. Como situa Anjos 
(2015), "nas mediações que deveriam efetivar o direito, essa existência lhes é sistematicamente desconstituída".

A execução dos direitos territoriais aos grupos quilombolas esbarra no cenário adverso à construção da cidadania para esses grupos reivindicantes, representado pela tensão constante da mídia e das propostas no legislativo (PEC 215 e a já julgada ADI 3.239), pela deslegitimação dos pleitos e pela modernização da desigualdade no acesso à terra, representada pela valorização do agronegócio e seu financiamento massivo pelo Estado, em contraposição às alardeadas promessas de efetivação de direitos territoriais e reformas estruturais aos quilombolas, indígenas. Diante desse quadro, a mobilização passa a constituir-se num caminho central para a interposição das demandas. A partir de 2011, as comunidades quilombolas constituem-se como um importante sujeito político em movimento no MA, realizando trocas de experiências, encontros em diferentes regiões do estado e articulações com outros sujeitos políticos (quebradeiras de coco babaçu, indígenas, posseiros, assentados de reforma agrária) também em situações precárias quanto à "viabilização de direitos". Por sua vez, essas comunidades optam por caminhos múltiplos de expressão de demandas, demonstrando um leque variado de orientações, desejos e representações próprias de acesso a direitos entre sujeitos, até outrora vistos como uniformes politicamente, dada sua pertença étnica comum. Isso evidencia a complexidade da análise no que tange aos (des)caminhos da mobilização quilombola no Maranhão.

Assim, pode-se falar em ganhos políticos, ora na exposição pública das situações vivenciadas, ora em processos de resistência e organização das comunidades quilombolas, na medida em que estes sujeitos múltiplos vêm criando formas de mobilizações não mais restritas a demandas atomizadas, expressas sobretudo, por pleitos destas comunidades frente a instâncias municipais, estaduais ou federais, mas iniciando recentemente a organização coletiva de uma frente de povos e comunidades tradicionais, responsável por aglutinar demandas e estratégias, denominada, "Teia de Povos e Comunidades Tradicionais" que chama atenção pela variedade de sujeitos ali presentes. 


\section{Referências}

ALBERTI, Verena; PEREIRA, Amilcar Araujo (OrgS.) Histórias do movimento negro no Brasil: depoimentos ao CPDOC, Rio de Janeiro: Pallas, 2007.

ALMEIDA, A. W. Quilombos: Repertório bibliográfico de uma questão redefinida (19951997) BIB, Rio de Janeiro, n. 45, p. 51-70, $1^{\circ}$ semestre de 1998.

ANJOS, J. C. Prólogo. Brustolin, C, Reconhecimento e Desconsideração: os territórios quilombolas sob suspeita. São Luís: EDUFMA, 2015.

ARRUTI, J. M. A emergência dos "remanescentes": notas para o diálogo entre indígenas e quilombolas. Mana, Rio de Janeiro, v.3 n.2, oct.,1997

BARBOSA, Milton. Reaja à violência racial. Jornal MNU, São Paulo, 1991.

BRUSTOLIN, Cíndia. Reconhecimento e Desconsideração: a regularização fundiária dos territórios quilombolas sob suspeita. São Luis: EDUFMA/Café e Lápis, 2015.

Comissão Pró-índio de São Paulo: http://www.cpisp.org.br/htm/leis/index.html, 2007.

DOMINGUES, Petrônio. Movimento Negro Brasileiro: alguns apontamentos históricos.

Revista Tempo, Niterói, p.100-122, 2007.

FURTADO, Marivânia Leonor Souza. Aquilombamento no Maranhão: um Rio Grande de (im)possibilidades. 2012. Tese (Doutoramento em Geografia) - Universidade Estadual Paulista, Programa de Pós-Graduação em Geografia, Presidente Prudente, 2012.

LEITE, Ilka Boaventura. Os quilombos no Brasil: questões conceituais e normativas. Etnográfica, Lisboa, v. 4, n.2, p. 333- 354, 2000.

PROJETO VIDA DE NEGRO. Vida de negro no Maranhão: uma experiência de luta, organização e resistência nos territórios quilombolas. São Luís: SMDH, CNN-MA, PVN, 2005 (Coleção Negro Cosme).

SILVA, Dimas Salustiano da. Frechal: cronologia da vitória de uma comunidade remanescente de quilombo; Constituição e diferença étnica: o problema jurídico das comunidades negras remanescentes de quilombos no Brasil. Boletim informativo NUER, Florianópolis: UFSC, 1996. , Dimas Salustiano da. Constituição e diferença étnica: o problema das 
comunidades negras remanescentes de quilombo no Brasil. Regulamentação de terras de negro no Brasil. Boletim Informativo do Nuer, Florianópolis: UFSC, 1996.

SANTOS, do Regina Coeli Benedito dos. Raça, sexualidade e política: um estudo da constituição de organizações lésbicas negras no Rio de Janeiro. 2006. Dissertação (Mestrado em Políticas Sociais) Universidade Federal Fluminense -: Programa de PósGraduação em Política Social, Niterói, 2006.

SOUSA, Igor Thiago Silva de. Processos de mobilização quilombola: a ACONERUQ e o MOQUIBOM no Maranhão. 2016.132 f. Dissertação (Mestrado em Antropologia Social) Universidade Federal de Santa Catarina, Programa de Pós-Graduação em Antropologia Social, Faculdade de Ciências Humanas, Florianópolis, 2016.

TRECCANI, Girolamo Domenico. Terras de Quilombo: caminhos e entraves do processo de titulação. Belém: Secretaria Executiva de Justiça. Programa Raízes, 2006.

Recebido em: 16/11/2017

Aprovado 24/04/2018

Universidade do Estado de Santa Catarina - UDESC

Centro de Ciências Humanas e da Educação - FAED

Revista PerCursos

Volume 19 - Número 39 - Ano 2018 revistapercursos@gmail.com 